\title{
IEEE 802.11b/g Practical Assessment Using a Low-Cost Quasi-Yagi Rectenna for Indoor RF Energy Harvesting
}

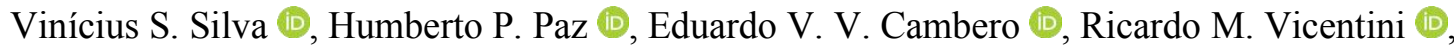 \\ Ricardo Q. Martins (D), Carlos E. Capovilla (D), Ivan R. S. Casella (D) \\ Universidade Federal do ABC (UFABC), Av. dos Estados 5001, Santo André, SP, Brasil \\ vinicius.santana@ufabc.edu.br,humberto.paz@ufabc.edu.br,eduardo.valdes@ufabc.edu.br, \\ ricardo.martinez@ufabc.edu.br, ricardo.queiroz@ufabc.edu.br,carlos.capovilla@ufabc.edu.br, \\ ivan.casella@ufabc.edu.br
}

\begin{abstract}
This article presents an experimental analysis of the use of signals transmitted by Wireless Local Area Networks (WLAN) based on the IEEE $802.11 \mathrm{~b} / \mathrm{g}$ standards for Radio Frequency Energy Harvesting (RFEH) applications in indoor environments employing a Quasi-Yagi Rectenna (QYR) topology. This analysis is a crucial point to distinguish the use of the IEEE 802.11b/g standards for ambient RFEH applications and contributes to the debate on the use of different types of energy available for free in modern society. For it, a dedicated setup, developed in a controlled environment to avoid any external interference, was built to carry out the programmed measurements. The results obtained indicate that IEEE $802.11 \mathrm{~b} / \mathrm{g}$ standards have great potential for applications in RFEH, with the IEEE 802.11b average power four times higher than IEEE 802.11g at the rectifier output.
\end{abstract}

Index Terms - Energy Harvesting, Quasi-Yagi Antenna, Radio Frequency, Rectenna, WiFi

\section{INTRODUCTION}

Radio Frequency Energy Harvesting (RFEH) has been widely studied in recent years as a power source for low power devices through the use of a rectenna, which is basically a circuit composed of an antenna or antenna array coupled to a Radio Frequency (RF) rectifier [1], [2]. The use of rectennas in Low Power Wide Area Networks (LPWANs), especially in hazardous or difficult to access places, where maintenance can be expensive or impractical, can be a good alternative to reduce the required maintenance cycles through automatic batteries recharging or even batteries-free operations [3], [4]. These strategies associated with the presence of RF signals transmitted from different sources (e.g. TV transmitters, cell phone base stations, wireless routers) have constantly driven the search for new more efficient rectennas designs.

Among the diversity of possible operating bands for powering LPWAN devices by using RFEH [5-9], the license-free $2.4 \mathrm{GHz}$ Industrial, Scientific, and Medical (ISM) band been shown to be very promising for indoors applications [10-13]. This frequency band is widely used by different communication technologies such as RF Identification (RFID), Bluetooth, ZigBee and Wireless Fidelity (WiFi) [1], [14], which means that there is a considerable amount of power available in this 
spectrum due to the dense exchange of information between the devices.

However, the use of this band presents some challenges such as the maximum transmission power of each communication system, which is limited by regulatory agencies [2], [15]; the spatial power density variations, which depend on the distance between the rectenna and the transmission source and the degrading effects of the wireless channel (e.g. propagation loss, multipath fading, among others) $[6],[16],[17]$; and the time power density variations, which are related to the signal transmission periods, inherent to each communication technology [18], [19].

On the other hand, optimal power transmission has bandwidth requirements opposite to that of the communication technologies. While communication systems usually employ a large bandwidth to increase their performance (e.g. to increase the data rate), Wireless Power Transfer (WPT) systems generally operate in an extremely narrow bandwidth to improve their performance [20], as in the case of using a Continuous Wave (CW) transmission. However, as illustrated in Fig. 1, the signal bandwidth and its Power Spectrum Density (PSD), associated with the narrow bandwidth of the rectifiers and their nonlinear behavior, make the characterization of the rectennas source-dependent.

Power

Source

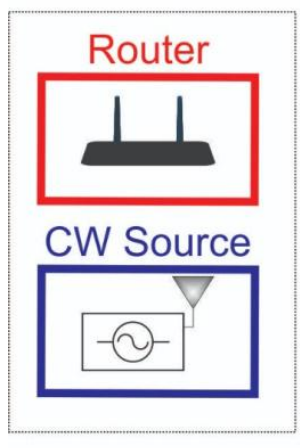

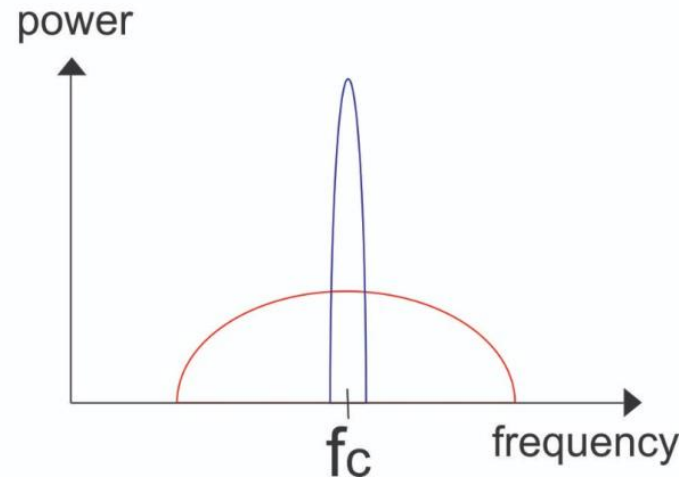

Fig. 1. Schematic of PSD distribution around a central frequency $\left(f_{c}\right)$ for different RF sources.

Thus, the use of rectennas for RFEH from indoor communication systems signals to power LPWAN devices has different concerns than those involved in the RFEH from CW signals [5], [21], [22], which represents an ideal WPT scenario. For instance, WiFi, which is in fact the Wireless Local Area Network (WLAN) technology used today, is specified in different ways within the IEEE 802.11 standard, each employing different transmission powers, data rates, modulation and encoding techniques, bandwidths and PSDs and, therefore, causing different impacts on the performance of the rectenna and, consequently, of the RFEH system.

In this way, the study of RFEH from WiFi signals (i.e. in accordance with IEEE 802.11 standard), transmitted in the form of bursts, are still necessary for an adequate evaluation of the performance of the rectenna in a more realistic indoor environment [23]. In [2] a way to optimize the use of the WiFi band was described, based on the maximization of the transmitted energy density in disposable time periods, considering that the latency of the communication channel is low. In [23], the traffic of the 
IEEE $802.11 \mathrm{~b}$ and IEEE $802.11 \mathrm{~g}$ networks was analyzed and the time to charge a supercapacitor was optimized based on the available energy, but without highlighting the differences in the use of each standard.

This shows that several RFEH studies using non-CW transmissions, based on the IEEE $802.11 \mathrm{~b}$ and IEEE $802.11 \mathrm{~g}$ standards, are still in progress. Typically, the choice of IEEE $802.11 \mathrm{~g}$ over IEEE $802.11 \mathrm{~b}$ is justified, for communication applications, among other things, by its higher data rate. However, this feature cannot be preferable for RFEH applications. Thus, due to the current high penetration of IEEE $802.11 \mathrm{~b}$ and IEEE $802.11 \mathrm{~g}$ standards for WLAN applications in different indoor environments (e.g. homes, businesses, and industries), it is essential to evaluate them separately to verify their operation from the point of view of the rectenna and RFEH performance.

In this context, to analyze the differences between these two standards for indoor RFEH applications, this work uses a low-cost Quasi-Yagi Rectenna (QYR) prototype and a common commercial WiFi router (compatible with both standards) to measure, inside an anechoic chamber, the variations of the output voltage $\left(\mathrm{V}_{\mathrm{o}}\right)$ of the rectenna over time at different distances. Thus, this study can be used as a starting point for the analysis of RFEH from signals of communication systems operating in bursts and for the study of traffic optimization of these systems for RFEH applications. Therefore, the comparison between the IEEE 802.11 standards aims to show how differences in signal transmission, such as frame structure, transmission rate, and modulation, influence RFEH performance.

This article was organized in the following order. In addition to this introduction, a description of the QYR prototype and its performance evaluation in a controlled CW environment are presented in section II. In section III, the essential characteristics of the IEEE $802.11 \mathrm{~b}$ and IEEE $802.11 \mathrm{~g}$ standards for RFEH applications are highlighted and the measurement system setup is characterized. In section IV, the obtained results are presented and analyzed in detail. Finally, in section V, the main conclusions are presented.

\section{QYR PROTOTYPE}

In this experimental analysis, the design of a QYR based on a Quasi-Yagi antenna (QY) was chosen, since this antenna has good characteristics of radiation pattern and gain [24], which makes it a good option for indoor applications.

The overall QYR structure is composed of the QY associated with a series rectifier circuit, connected by a SMA male to SMA male connector, as shown in Fig. 2. The use of a series rectifier circuit was chosen to increase the rectenna efficiency in low levels of the RF received power [25]. All the QYR elements are designed over the same low-cost $1.6 \mathrm{~mm}$-thickness FR-4 substrate with a $\tan \delta$ (loss tangent) of 0.02 and $\varepsilon_{\mathrm{r}}$ (relative permittivity) of 4.5. The rectifier and QY designs were optimized with the Keysight Advanced Design System (ADS) software. 


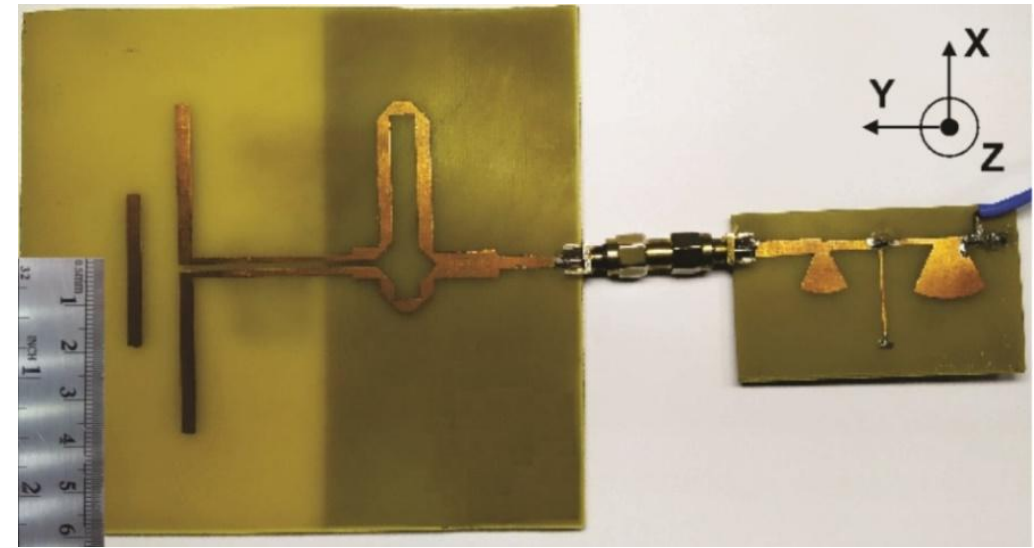

Fig. 2. Low-cost QYR prototype.

\section{A. Rectifier}

The rectifier input impedance and efficiency, for the specific frequency and power operational ranges, are critical parameters for any rectenna development. Aiming these characteristics as the main design goal, the chosen circuit topology is based on the series rectifier, as shown in Fig. 3a. This rectifier is often addressed in the literature [5], [26], [27] and it presents a higher efficiency when compared to voltage multiplier rectifier topologies, for low input power levels $\left(\mathrm{P}_{\text {in }}\right)$ [25]. Additionally, when it is compared with more complex rectifier topologies, as voltage doubler and full wave rectifiers, it requires a lower number of components, also contributing to decrease the prototype cost. The layout of the rectifier is shown in Fig. 3b (for more design details, see [28]).

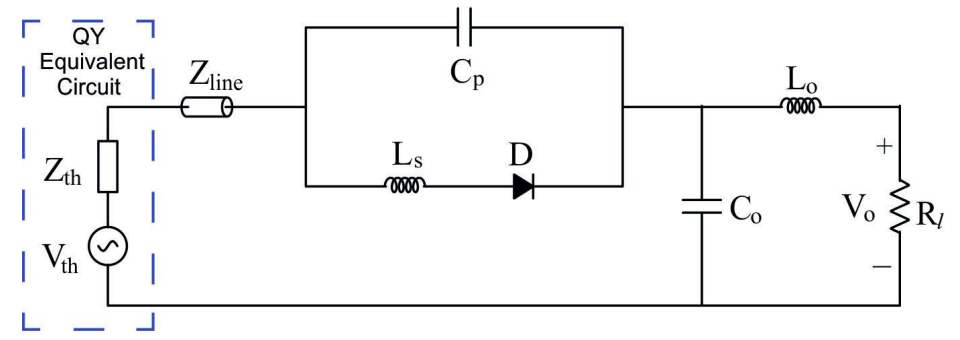

(a)

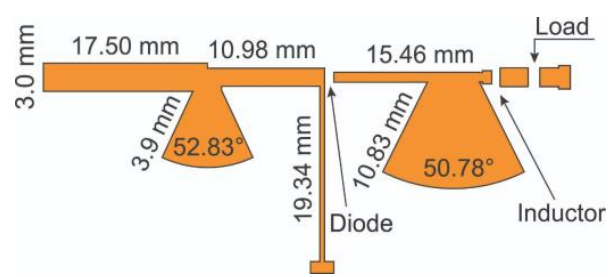

(b)

Fig. 3. Series rectifier circuit: (a) schematic and (b) layout.

The series rectifier output filter is composed by a choke inductor $\left(\mathrm{L}_{\mathrm{o}}\right)$ connected in series with the load $\left(R_{l}\right)$, and a microstrip radial stub capacitance $\left(\mathrm{C}_{\mathrm{o}}\right)$. The SMS7630-079LF diode (D) parasitic capacitance and inductance are, respectively, defined as $C_{p}$ and $L_{s}$ [29], [30]. The input impedance is set to $50 \Omega$, making use of a microstrip transmission lines $\left(Z_{\text {line }}\right)$, and the $\mathrm{QY}$ is modeled by its equivalent Thévenin circuit, formed by $\mathrm{V}_{\text {th }}$ and $\mathrm{Z}_{\mathrm{th}}$. Both, $\mathrm{R}_{l}$ (optimum load of $3.3 \mathrm{k} \Omega$ ) and $\mathrm{L}_{\mathrm{o}}(10 \mu \mathrm{H}$ ), are general purpose Surface Mounted Device (SMD) components usually used in RF front-end circuits [28].

The RF to DC conversion efficiency ( $\eta_{\mathrm{RF}-\mathrm{DC}}$ ), which is a function of the frequency, $\mathrm{P}_{\mathrm{in}}$, and $R_{l}[30]$, is defined by (1), where $\mathrm{P}_{\mathrm{o}}$ is the output power over $R_{l}$. 


$$
\eta_{\mathrm{RF}-\mathrm{DC}}=\frac{\mathrm{P}_{\mathrm{o}}}{\mathrm{P}_{\mathrm{in}}}=\frac{\mathrm{V}_{\mathrm{o}}^{2}}{\mathrm{R}_{l} \mathrm{P}_{\mathrm{in}}}
$$

Consequently, to evaluate $\eta_{\mathrm{RF}-\mathrm{DC}}$, the Keysight N931A RF signal generator is connected to the rectifier, and $\mathrm{V}_{\mathrm{o}}$ is measured using the Tektronix DMM4040 precision multimeter. In addition, to confirm the output power levels of the N9310, whose small variations can cause a strong impact on the efficiency measurements, the power levels are calibrated using a Rohde \& Schwarz NRP-Z91 power sensor. Furthermore, to demonstrate that the circuit is also matched for $\mathrm{P}_{\text {in }}$ levels around the design point, it becomes important to measure the reflection coefficient $\left(S_{11}\right)$ parameter related to $P_{\text {in }}$, using a Rohde \& Schwarz ZVB 8 Network Analyzer and sweeping $P_{\text {in }}$ from -30 to $-10 \mathrm{dBm}$, as shown in Fig. 4, with the best $\left|S_{11}\right|$ matching at $-18 \mathrm{dBm}$. The $\eta_{\mathrm{RF}-\mathrm{DC}}$ of the series rectifier is also presented in Fig. 4, resulting in efficiency over $18 \%$ at $-20 \mathrm{dBm}$. The rectifier is matched for the whole analyzed $\mathrm{P}_{\text {in }}$ range at $2.45 \mathrm{GHz}$, considering $\left|\mathrm{S}_{11}\right| \leq-10 \mathrm{~dB}$, where more than $90 \%$ of the power supplied will be transmitted to the rectifier [31].

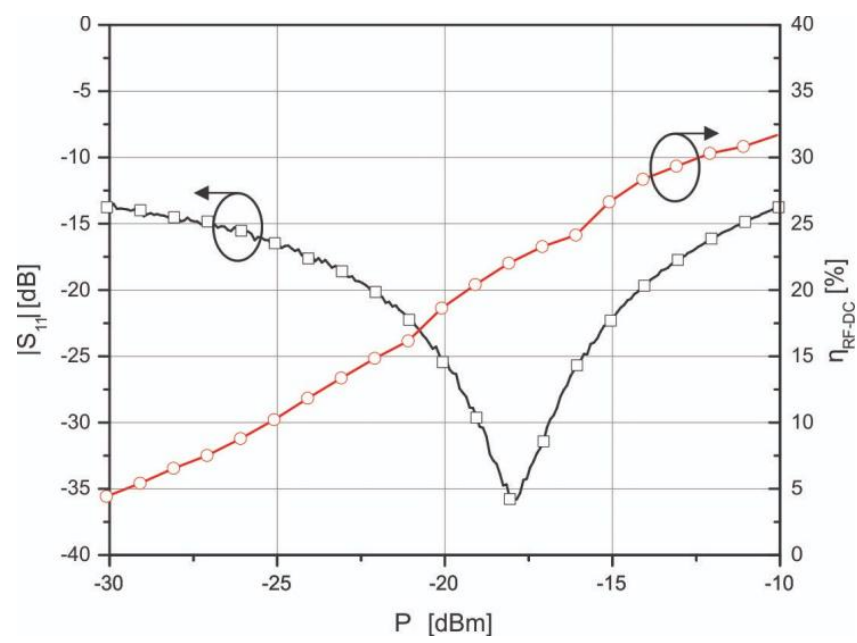

Fig. 4. Measured $\left|S_{11}\right|$ and $\eta_{R F-D C}$ for different $P_{\text {in }}$ levels at $2.45 \mathrm{GHz}$.

\section{B. QY Antenna Design}

The QY is a classical radiating element that was proposed by the first time in [32]. Its structure is based on the classic Yagi-Uda antenna topology, featuring a dipole as a driver element, a parasitic structure that works as a director and a truncated ground plane reflector [24]. The combination of resonant elements as the driver, director, and truncated ground plane reflector designed for slightly different frequencies, in addition with a broadband microstrip to Coplanar Stripline (CPS) transition (balun) make this element a microwave broadband device [33-35].

The QY layout is adapted from previous work [36] , presenting a total area of 110x105 mm². The QY layout with its final dimensions is shown in Fig. 5. 


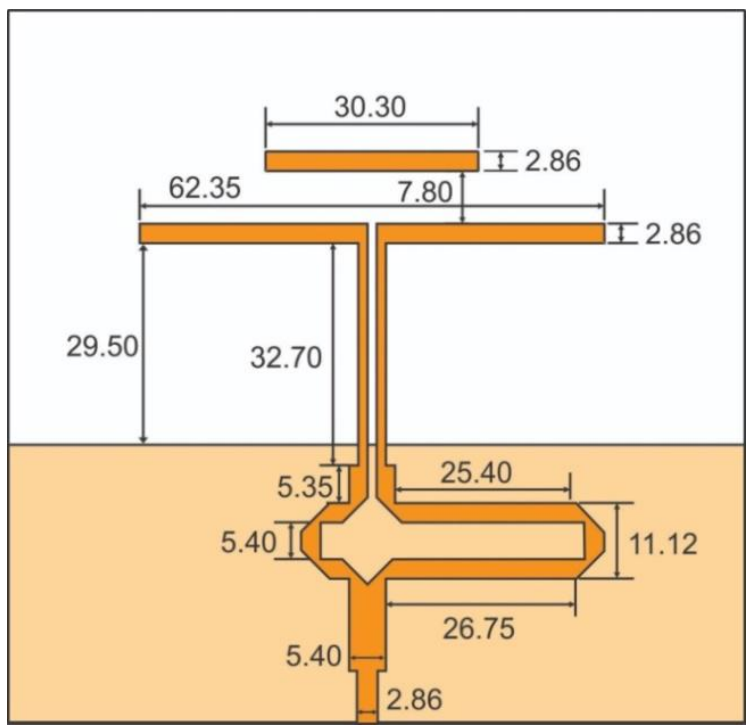

Fig. 5. QY layout (dimensions in $\mathrm{mm}$ ).

As a broadband antenna, the QY design optimization criteria are not associated to just one specific frequency, but to the entire operational band. Therefore, to attest its good performance, a current density analysis was implemented and the results can be seen in Fig. 6., including the adopted $2.45 \mathrm{GHz}$ RFEH frequency (Fig. 6c).

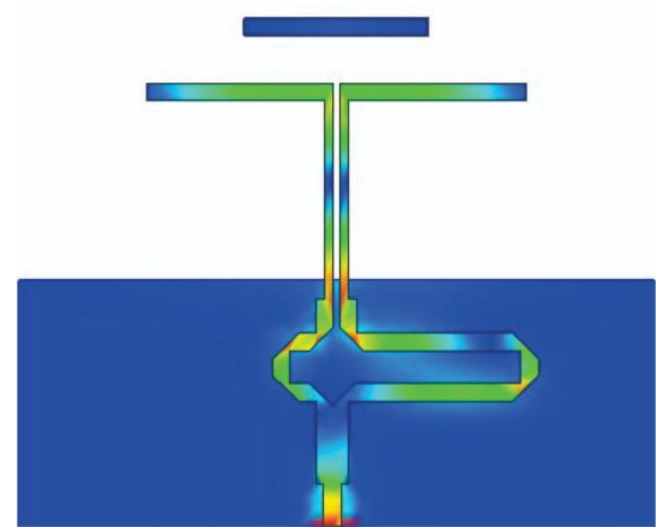

(a)

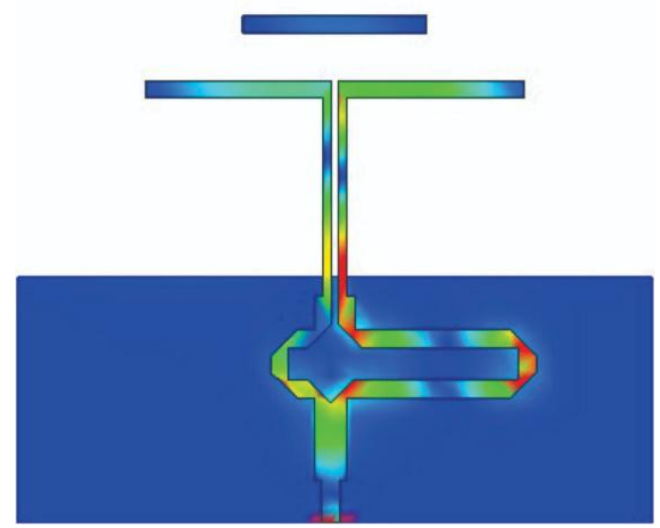

(c)

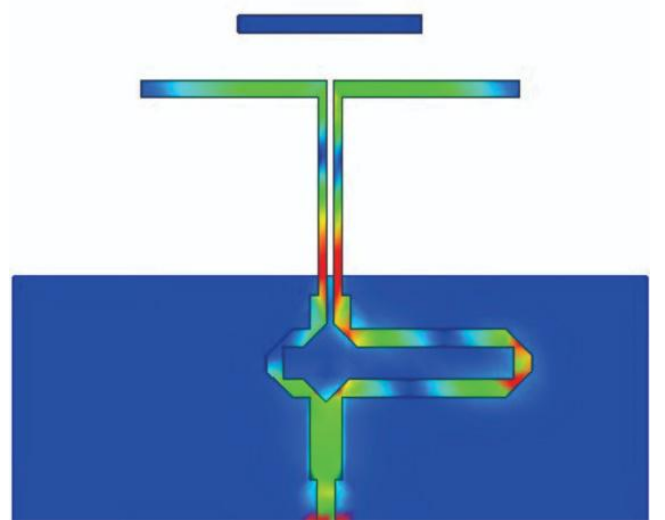

(b)

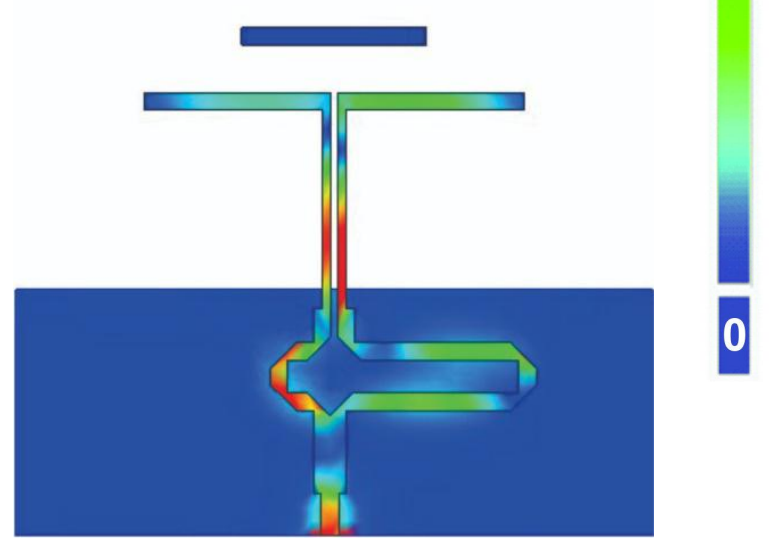

(d)

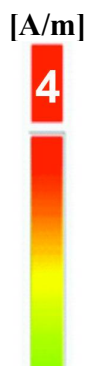

Fig. 6. Current density in linear scale at (a) 1.9, (b) 2.2, (c) 2.45 and (d) $2.6 \mathrm{GHz}$. 
The $\left|\mathrm{S}_{11}\right|$ of the QY and the rectifier circuit as a function of frequency, within the range of interest, can be seen in Fig. 7. It is important to note that due to the nonlinear behavior of the diode impedance, the rectifier measurements were done for three different $P_{\text {in }}$ levels, centered at $-20 \mathrm{dBm}$ with a $20 \mathrm{~dB}$ span.

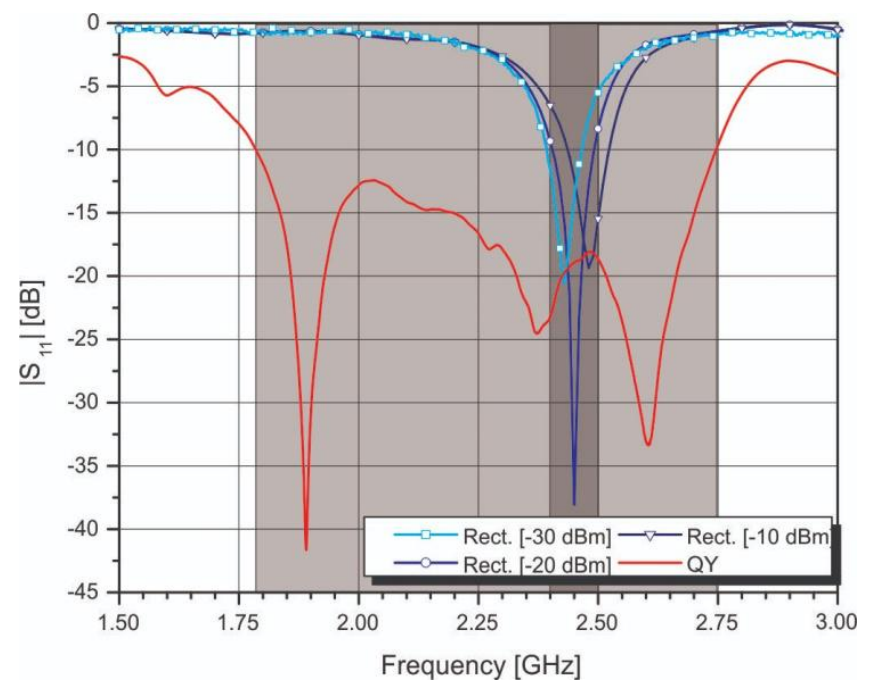

Fig. 7. $\left|\mathrm{S}_{11}\right|$ of the $\mathrm{QY}$ and the rectifier.

The bandwidth of the QY, with three resonant deeps, according to Fig. 7 is approximately $1 \mathrm{GHz}$ (light shade). This bandwidth (region $\left|\mathrm{S}_{11}\right| \leq-10 \mathrm{~dB}$ for $50 \Omega$ impedance) is adequate to ensure that any displacement of the $\mathrm{S}_{11}$, produced by $\mathrm{P}_{\text {in }}$ variations due to the non-linear behavior of the Schottky diode, does not cause any significant impedance mismatching between the antenna and rectifier [31]. In addition, the bandwidth of the IEEE 802.11 standard operating in $2.4 \mathrm{GHz}$ (dark shading) is entirely covered by the bandwidths of the rectifier and the QY in the $\mathrm{P}_{\text {in }}$ adopted range, as desired in a real operating condition.

The QY antenna gain was measured in the anechoic chamber (ETS-Lindgren - model Spacesaver H26) of the Information and Communication Laboratory (LIC) at the Federal University of ABC (UFABC). The antenna presented a measured gain of $3.8 \mathrm{dBi}$ and efficiency of $74 \%$ at $2.45 \mathrm{GHz}$. To complete the QY characterization, the measured 3D and 2D radiation patterns (normalized $\mathrm{dB}$ scale) are presented in the Fig. 8 and Fig. 9, respectively. In Fig. 8, the E-plane and H-plane (X-Y and Z-Y, respectively, in reference to Fig. 2) are in evidence. In the Fig. 9a is presented the total field analysis, while Fig. $9 \mathrm{~b}$ shows the low cross-polarization for this prototype, which is less than $-15 \mathrm{~dB}$. These results endorse the adoption of this planar antenna for the proposed analysis. 

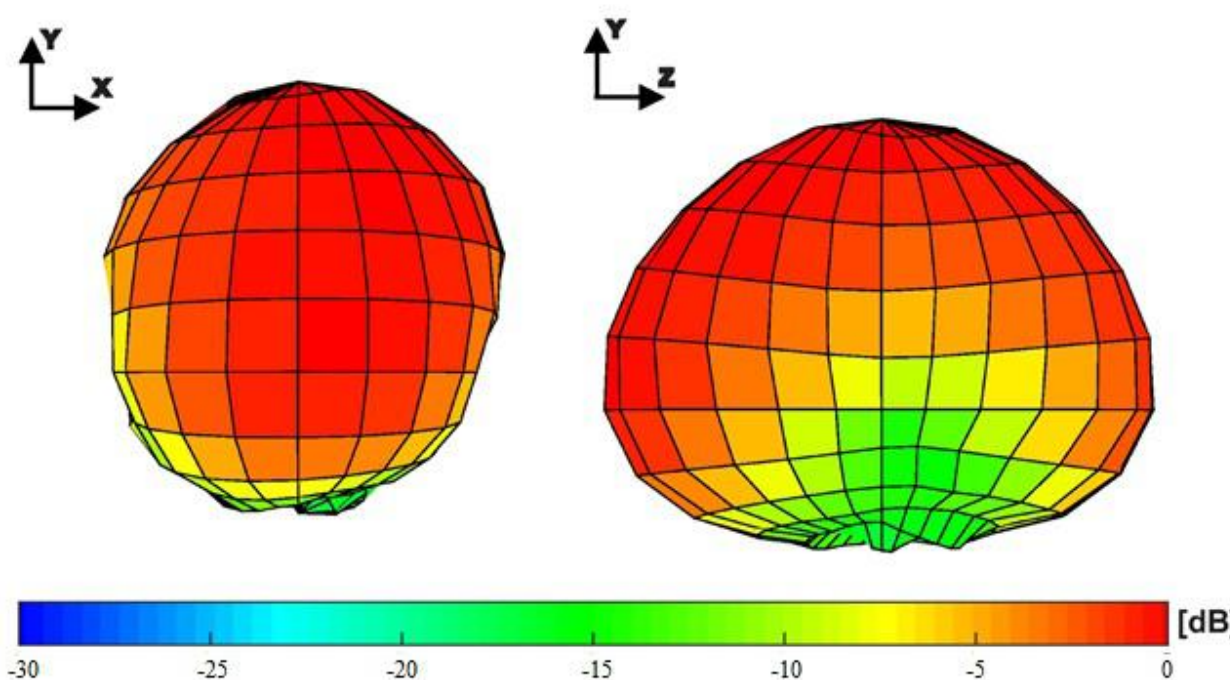

Fig. 8. Measured 3D radiation pattern of the QY at $2.45 \mathrm{GHz}$.

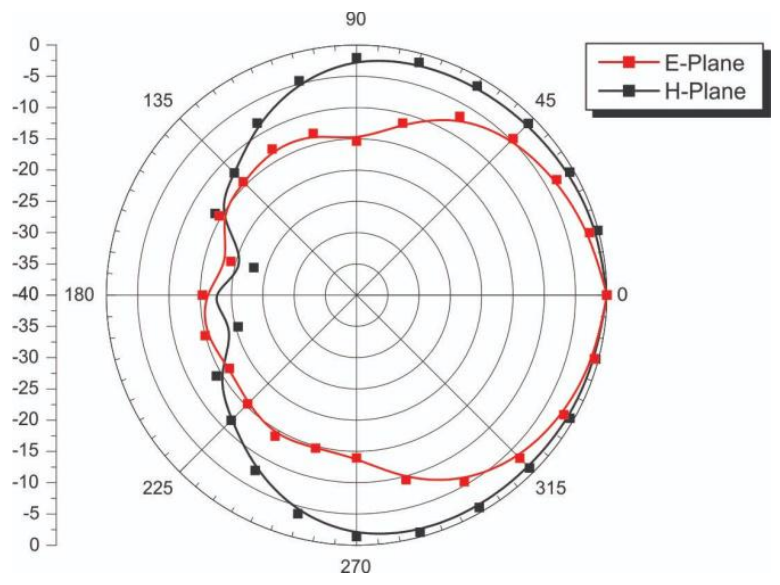

(a)

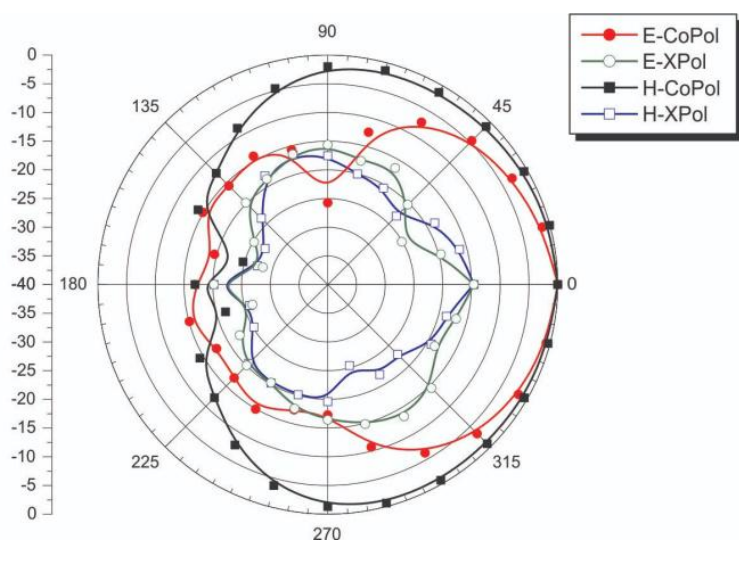

(b)

Fig. 9. Measured radiation pattern of the QY at $2.45 \mathrm{GHz}$. In (a) is presented the total field analysis, and in (b) the fields are decomposed into its $\mathrm{Co}(\mathrm{CoPol})$ and $\mathrm{Cross}(\mathrm{XPol})$ polarization components.

\section{QYR Characterization}

After the individual characterization of each element of the rectenna (antenna and rectifier), it is necessary to characterize the assembled QYR. For this purpose, a measurement setup was implemented inside an anechoic chamber, employing a $\mathrm{CW}$ transmission signal at $2.45 \mathrm{GHz}$ with linear polarization [37]. The average power density $\left(\mathrm{S}_{\mathrm{AV}}\right)$ was adjusted from 0.05 to approximately $6 \mu \mathrm{W} / \mathrm{cm}^{2}$, for a link distance of $40 \mathrm{~cm}$, which is sufficient to reach the far-field zone from the transmission antenna (an identical QY) and the elements were orientated to guarantee a line-of-sight propagation in co-polarization. The results are presented in Fig. 10. 


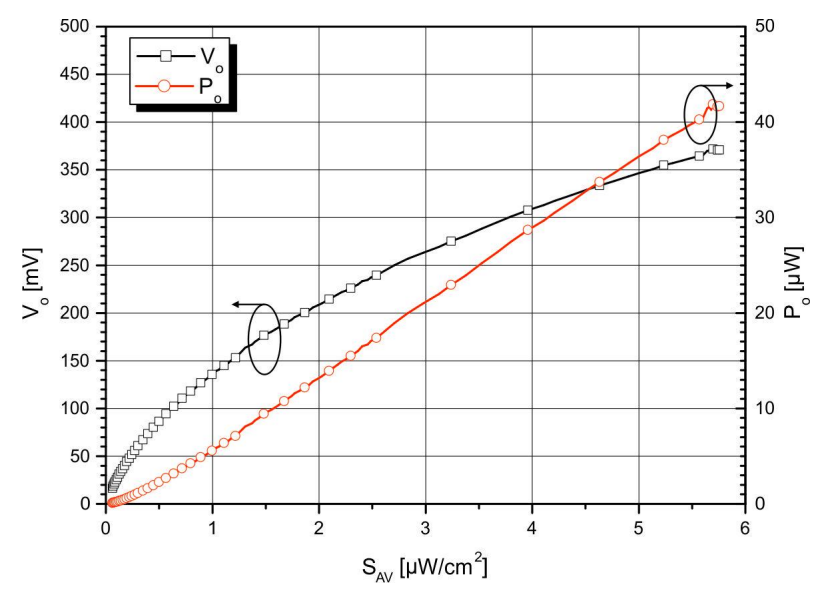

(a)

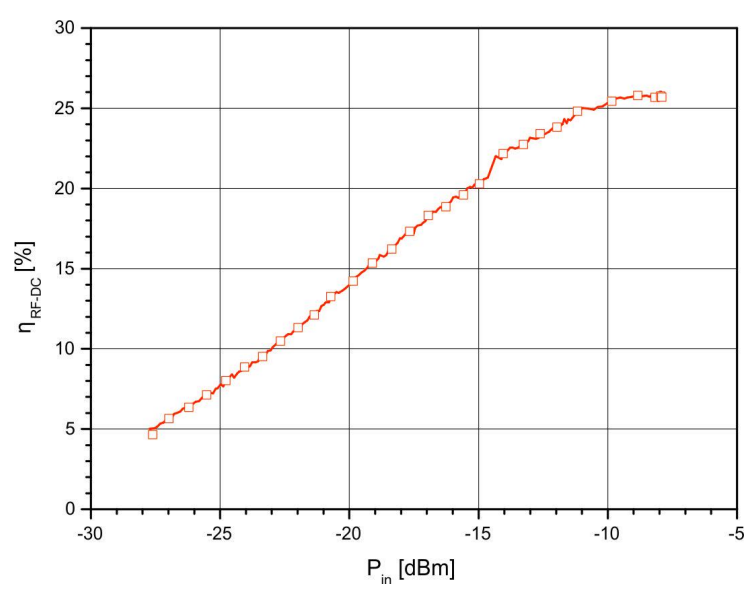

(b)

Fig. 10. QYR performance analysis considering a $\mathrm{CW}$ signal. (a) $\mathrm{V}_{\mathrm{o}}$ and $\mathrm{P}_{\mathrm{o}}$, and (b) $\eta_{\text {RF-DC. }}$

To calculate the $\eta_{\text {RF-DC }}$ of the QYR (Fig. 10b), the $P_{\text {in }}$ values used in (1) were obtained through the Friis equation, considering the characteristics of the antenna link of the measurement setup. The slight decrease observed in the $\eta_{\text {RF-DC }}$ measure of QYR compared to that obtained with the rectifier alone (about 7\% reduction) was expected due to the interactions between the antenna and rectifier impedances and the addition of a SMA male to SMA male connector. Despite this, the approximate values of $350 \mathrm{mV}$ and $37 \mu \mathrm{W}$, respectively for $\mathrm{V}_{\mathrm{o}}$ and $\mathrm{P}_{\mathrm{o}}$, in an environment with $5 \mu \mathrm{W} / \mathrm{cm}^{2}$ (Fig. 10a), endorse the good performance of QYR in a WPT context.

However, the $\mathrm{CW}$ analysis is not the most adequate to evaluate the performance of a rectenna for RFEH from signals of commercial communication systems in indoor environments. Thus, in the next sections, a measurement setup based on a commercial WiFi network (employing a router compatible to the IEEE $802.11 \mathrm{~b}$ and IEEE $802.11 \mathrm{~g}$ standards) and a QYR performance analysis will be presented.

\section{SETUP DESCRIPTION}

Before describing the measurement setup that will be used to assess the performance of the QYR for RFEH from the WiFi signal transmitted by a router, the main relevant parameters of the evaluated IEEE 802.11 standards will be briefly presented: the IEEE $802.11 \mathrm{~b}$ has a bit rate from 1 to $11 \mathrm{Mbps}$, based on the Complementary Code Keying (CCK) modulation with a spectral power mask of 10 $\mathrm{dBm} / \mathrm{MHz}$. In addition, it is important to note that modern IEEE 802.11 devices maintain compatibility with previous versions of this standard, which guarantees continuous availability of the IEEE $802.11 \mathrm{~b}$ standard. On the other hand, the IEEE $802.11 \mathrm{~g}$ is based on Orthogonal Frequency Division Multiplexing (OFDM) modulation, with bit rate ranging from 6 to $54 \mathrm{Mbps}$, and it is limited by a $5 \mathrm{dBm} / \mathrm{MHz}$ spectral power mask [38]. A higher bit rate is a desirable feature from the point of view of the communication system. However, for the same packet size, as the rate varies, the packet transmission period varies.

In order to carry out the proposed analyzes, a router with high configuration capacity is required. Thus, the D-Link DIR-610N + commercial router was chosen, which allows changing several 
Journal of Microwaves, Optoelectronics and Electromagnetic Applications, Vol. 20, No. 1, March 2021

DOI: http://dx.doi.org/10.1590/2179-10.1590/2179-10742021v20i11052

parameters of both evaluated standards, such as the choice of the standard to be used, the operating channel, the bandwidth and the maximum Effective Isotropic Radiated Power (EIRP). In this study, for a fair comparison, the same parameters values were selected for both standards.

Aiming to analyze the differences in RFEH performance of using the IEEE 802.11b and IEEE 802.11g standards, it is essential to characterize the measurement setup in an interference-free environment, avoiding a wrong understanding of the characteristics of the standards for the specified boundary conditions and to ensure repeatability.

In this way, the measurement setup was also built inside of the anechoic chamber of the LIC (previously used for CW measurements), as described in Fig. 11a. In order to ensure that the router transmits signal continuously, two laptops were connected to the WiFi network, forming a support link so that one of them transmits data continuously to the other. Both were positioned $1.5 \mathrm{~m}$ away from the router and in the opposite direction of the rectenna. Its position and the use of absorbers ensure that the signals from the laptops reach the QYR with attenuation higher than $50 \mathrm{~dB}$ in relation to the signal received from the router, in addition to maintaining the signal power transmitted by the router at maximum.

A client-server software was developed to establish a communication link between the two laptops over the WiFi network (support link) using a specific IP address (Internet protocol). Using this software, it is possible to send any desired information from one computer to another via the WiFi router. To ensure continuous data transmission through the router during measurements, a long, high entropy data file was used.

On the measurement link, the QYR and the router were aligned, so that the direction of highest gain of the QYR pointed towards the router. The $\mathrm{V}_{\mathrm{o}}$ measurements were performed for a separation of 0.25 , $0.5,1$ and $1.5 \mathrm{~m}$ between the QYR and the router. The multimeter, used to measure $\mathrm{V}_{\mathrm{o}}$, was positioned about $1 \mathrm{~m}$ from the link. The measurement and support links are shown in Fig. $11 \mathrm{~b}$ and Fig. $11 \mathrm{c}$, respectively. 


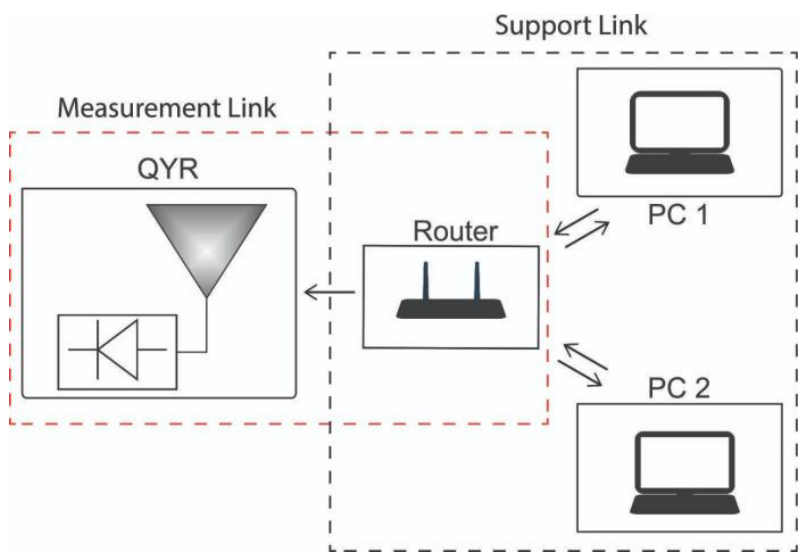

(a)

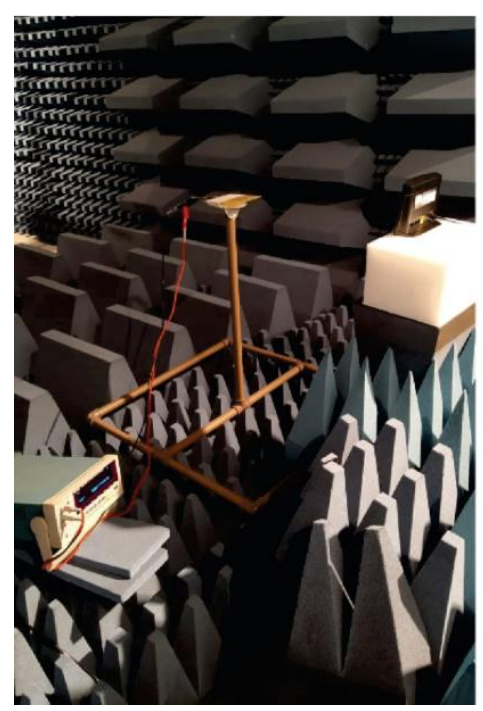

(b)

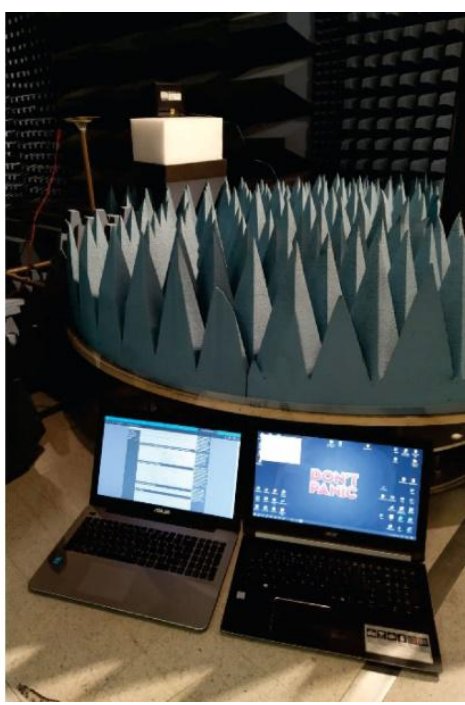

(c)

Fig. 11. Measurement setup (a) block diagram, (b) measurement link and (c) support link.

\section{ANALYSIS OF THE RESULtS}

As an initial evaluation, the signal transmitted by the router for a bandwidth of $20 \mathrm{MHz}$ was measured on a Rohde \& Schwarz FS315 spectrum analyzer in order to determine, for both evaluated standards, the RF power received by an isotropic antenna at $1 \mathrm{~m}$ from the router, in addition to their respective PSDs. Among the various channel options available for these standards, channel 9 (central frequency at $2.452 \mathrm{GHz}$ ) was chosen due to its proximity to the central frequency of the standards (2.45 GHz). Fig. 12a and Fig. 12b show the instantaneous PSD of each evaluated standard. 


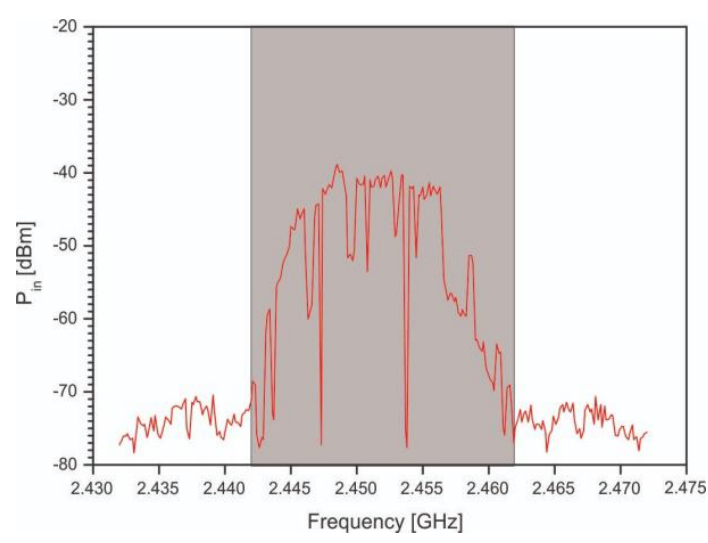

(a)

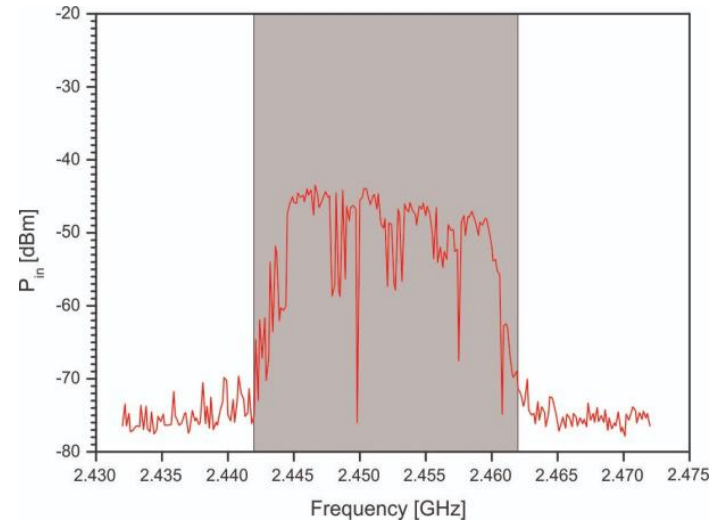

(b)

Fig. 12. PSD for one meter link for (a) IEEE $802.11 \mathrm{~b}$ and (b) IEEE $802.11 \mathrm{~g}$ standards.

As can be seen in Fig. 12a and Fig. 12b, each standard has a different PSD. As IEEE 802.11b (Fig. 12a) uses CCK spread spectrum modulation, its PSD after the wireless channel (gray shading) has larger spectral components at central frequencies that decrease as they move away from the central frequency (according to a $\operatorname{sinc}(|f|)^{2}$ function), which for simplicity can be represented by a spectral mask similar to a bowler hat. On the other hand, as the IEEE 802.11g (Fig. 12b) uses OFDM modulation, its PSD (gray shading) has almost uniform spectral components, which can be represented by a rectangular spectral mask. In a quantitative analysis, for the different distances $(0.25$, $0.5,1$, and $1.5 \mathrm{~m}$ ), the IEEE $802.11 \mathrm{~b}$ always resulted in an available average power of 2 to $3 \mathrm{~dB}$ above the IEEE $802.11 \mathrm{~g}$, for the proposed setup.

Based on the difference in PSD performance between the evaluated standards, a comparative analysis of the temporal variation of $\mathrm{V}_{\mathrm{o}}$ between them was performed, considering a separation of $0.5 \mathrm{~m}$ between the WiFi router and the QYR. The results obtained are shown in Fig. 13.

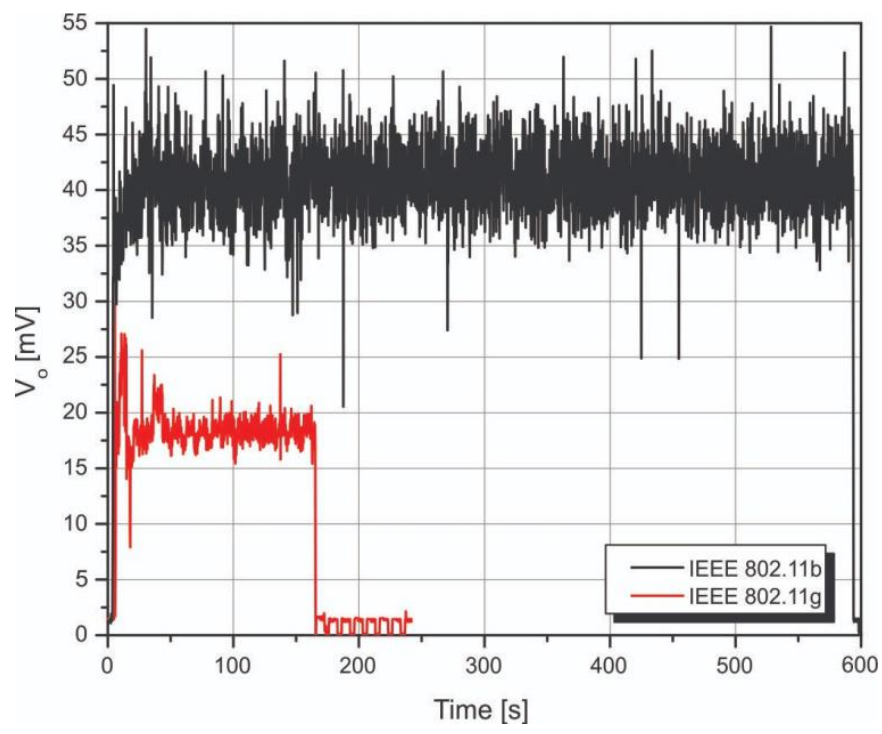

Fig. 13. QYR measured $\mathrm{V}_{\mathrm{o}}$ at $0.5 \mathrm{~m}$, using channel 9 and a $3.3 \mathrm{k} \Omega$ load.

The IEEE 802.11b standard has a much longer packet transmission period (approximately four times), and it also generates a higher $\mathrm{V}_{\mathrm{o}}$ (approximately two times). To improve the comparison 
between the RFEH performance of the QYR under the assessed standards, some new metrics were defined. The average voltage $\left(\mathrm{V}_{\text {avg }}\right)$ is calculated by the mean $\mathrm{V}_{\mathrm{o}}$ during the period of activity of the router. For this purpose, a threshold voltage is defined, and only the $\mathrm{V}_{\mathrm{o}}$ values between the first and the last sample above the threshold voltage are considered in the analysis. The average power $\left(\mathrm{P}_{\text {avg }}\right)$ is calculated by the ratio between the $\mathrm{V}_{\text {avg }}$ squared and the $\mathrm{R}_{l}(3.3 \mathrm{k} \Omega)$. Finally, the energy $(\mathrm{E})$ is calculated by the product between $\mathrm{P}_{\text {avg }}$ and the router active period. The QYR measurements using these metrics are shown in TABLE I.

TABLE I. QYR ENERGY HARVESTING RESULTS FOR CHANNEL 9.

\begin{tabular}{ccccccc}
\hline \multirow{2}{*}{ Distance $[\mathbf{m}]$} & \multicolumn{2}{c}{$\mathbf{V}_{\text {avg }}[\mathbf{m V}]$} & \multicolumn{2}{c}{$\mathbf{P}_{\text {avg }}[\mathbf{n W}]$} & \multicolumn{2}{c}{$\mathbf{E}[\boldsymbol{\mu J}]$} \\
& $\mathbf{8 0 2 . 1 1 b}$ & $\mathbf{8 0 2 . 1 1 g}$ & $\mathbf{8 0 2 . 1 1 b}$ & $\mathbf{8 0 2 . 1 1 g}$ & $\mathbf{8 0 2 . 1 1 b}$ & $\mathbf{8 0 2 . 1 1 g}$ \\
\hline 0.25 & 67.33 & 37.91 & 1373.60 & 435.48 & 778.66 & 77.00 \\
0.5 & 40.74 & 18.54 & 502.93 & 104.16 & 298.68 & 16.87 \\
1 & 17.33 & 9.26 & 91.05 & 25.96 & 59.83 & 5.79 \\
1.5 & 5.93 & 3.02 & 10.67 & 2.77 & 6.81 & 0.38 \\
\hline
\end{tabular}

The study presented in Fig. 13, for a distance of $0.5 \mathrm{~m}$, can be expanded to provide a more in-depth quantitative discussion taking into account other distances. The results obtained are presented in TABLE I. For distances from 0.5 to $1.5 \mathrm{~m}$ the $\mathrm{V}_{\text {avg }}$ of the QYR obtained when IEEE $802.11 \mathrm{~b}$ is used is 2 times higher than that obtained when IEEE $802.11 \mathrm{~g}$ is used, as previously discussed and, as a result, the $\mathrm{P}_{\text {avg }}$ obtained through IEEE $802.11 \mathrm{~b}$ is 4 times that through IEEE $802.11 \mathrm{~g}$. For the distance of $0.25 \mathrm{~m}$, the variation in these ratios is probably due to the near field interactions between QYR and the router.

It is important to note that in practice the active period of the router can vary randomly, as it depends, among other things, on the random characteristics of the wireless channel and, consequently, on the bit error rate (which can cause an increase in the number of retransmissions). Therefore, the power ratio between the standards may also vary randomly depending on the characteristics of the wireless channel.

\section{CONCLUSIONS}

This work presents a complete RFEH analysis of the WiFi network signals, according to the IEEE $802.11 \mathrm{~b}$ and IEEE $802.11 \mathrm{~g}$ standards. A QYR prototype was designed and characterized and measurements were performed inside an anechoic chamber, varying the distance between a $\mathrm{WiFi}$ router and the QYR to fully assess its functioning from the point of view of RFEH when each of the evaluated standards is used.

The evidence from this research implies that the IEEE $802.11 \mathrm{~b}$ standard is advantageous compared to the IEEE $802.11 \mathrm{~g}$ standard when the focus is on RFEH. It was demonstrated that $\mathrm{V}_{\mathrm{o}}$ and $\mathrm{P}_{\text {avg }}$ obtained with the use of IEEE $802.11 \mathrm{~b}$ are, respectively, of the order of two and four times higher than those obtained with the use of IEEE 802.11g. Additionally, due to the lower data transmission rate of IEEE $802.11 \mathrm{~b}$ and, consequently, the longer exposure time for the transmission of information, 
Journal of Microwaves, Optoelectronics and Electromagnetic Applications, Vol. 20, No. 1, March 2021

DOI: http://dx.doi.org/10.1590/2179-10.1590/2179-10742021v20i11052

the energy transmitted during the communication period will also be higher when compared to the IEEE 802.11g.

In this way, considering these characteristics, it can be concluded that an interesting advantage can be obtained from the RFEH point of view if a control method is developed on the router to enable the IEEE $802.11 \mathrm{~b}$ (or another standard employing similar characteristics) when the priority is RFEH or when there is no data information to be transmitted (e.g., for a faster recharge of the battery of low power devices) and to enable IEEE $802.11 \mathrm{~g}$ only when the priority is to transmit data at higher rates.

\section{ACKNOWLEDGMENT}

This research was partially supported by CNPq (309848/2018-0), CAPES (Finance Code 001), and FAPESP (2019/25866-7).

\section{REFERENCES}

[1] U. Olgun, C. Chen e J. L. Volakis, "Design of an efficient ambient Wi-Fi energy harvesting system," IET Microwaves, Antennas Propagation, vol. 6, pp. 1200-1206, Aug. 2012.

[2] V. Talla, B. Kellogg, B. Ransford, S. Naderiparizi, S. Gollakota e J. R. Smith, "Powering the Next Billion Devices with Wi-Fi," in Proceedings of the 11th ACM Conference on Emerging Networking Experiments and Technologies, New York, NY, USA, 2015.

[3] T. Soyata, L. Copeland e W. Heinzelman, "RF Energy Harvesting for Embedded Systems: A Survey of Tradeoffs and Methodology," IEEE Circuits and Systems Magazine, vol. 16, pp. 22-57, 2016.

[4] C. Shao, H. Roh, T. Kim e W. Lee, "Multisource wireless energy harvesting-based medium access control for rechargeable sensors," IEEE Transactions on Consumer Electronics, vol. 62, pp. 119-127, May. 2016.

[5] V. Palazzi, J. Hester, J. Bito, F. Alimenti, C. Kalialakis, A. Collado, P. Mezzanotte, A. Georgiadis, L. Roselli e M. M. Tentzeris, "A Novel Ultra-Lightweight Multiband Rectenna on Paper for RF Energy Harvesting in the Next Generation LTE Bands," IEEE Transactions on Microwave Theory and Techniques, vol. 66, pp. 366-379, Jan. 2018.

[6] S. Kim, R. Vyas, J. Bito, K. Niotaki, A. Collado, A. Georgiadis e M. M. Tentzeris, “Ambient RF Energy-Harvesting Technologies for Self-Sustainable Standalone Wireless Sensor Platforms," Proceedings of the IEEE, vol. 102, pp. 16491666, Nov. 2014.

[7] S. Chandravanshi e M. J. Akhtar, "An efficient dual-band rectenna using symmetrical rectifying circuit and slotted monopole antenna array," International Journal of RF and Microwave Computer-Aided Engineering, vol. 30, Jan. 2020.

[8] T. Moura, N. Borges de Carvalho e P. Pinho, "High-efficiency D-TV energy harvesting system for low-input power," Wireless Power Transfer, vol. 3, pp. 34-42, Mar. 2016.

[9] I. Adam, M. N. M. Yasin, H. A. Rahim, P. J. Soh e M. F. Abdulmalek, "A compact dual-band rectenna for ambient RF energy harvesting," Microwave and Optical Technology Letters, vol. 60, p. 2740-2748, Oct. 2018.

[10] Y. Chen e C. Chiu, "Maximum Achievable Power Conversion Efficiency Obtained Through an Optimized Rectenna Structure for RF Energy Harvesting," IEEE Transactions on Antennas and Propagation, vol. 65, pp. 2305-2317, May 2017.

[11] M. Palandöken, "Microstrip antenna with compact anti-spiral slot resonator for $2.4 \mathrm{GHz}$ energy harvesting applications," Microwave and Optical Technology Letters, vol. 58, p. 1404-1408, Mar. 2016.

[12] S. Lin, C. Hsieh, C. Chang e T. Jong, "Design and implementation of planar rectenna for ISM-band application," in 2015 European Microwave Conference (EuMC), 2015.

[13] S. K. Divakaran, D. D. Krishna e Nasimuddin, "RF energy harvesting systems: An overview and design issues," International Journal of RF and Microwave Computer-Aided Engineering, vol. 29, p. e21633, Dec. 2018.

[14] W. M. Khan e I. A. Zualkernan, "SensePods: A ZigBee-Based Tangible Smart Home Interface," IEEE Transactions on Consumer Electronics, vol. 64, pp. 145-152, May. 2018.

[15] H. Jabbar, Y. S. Song e T. T. Jeong, "RF energy harvesting system and circuits for charging of mobile devices," IEEE Transactions on Consumer Electronics, vol. 56, pp. 247-253, Feb. 2010.

[16] H. Hong, X. Cai, X. Shi e X. Zhu, "Demonstration of a highly efficient RF energy harvester for Wi-Fi signals," in 2012 International Conference on Microwave and Millimeter Wave Technology (ICMMT), 2012.

[17] P. Pereira, R. C. M. Pimenta, R. Adriano, G. L. F. Brandão e U. C. Resende, "Antenna impedance correction for low power energy harvesting devices," in 2017 SBMO/IEEE MTT-S International Microwave and Optoelectronics 
Conference (IMOC), 2017.

[18] J. Mišić e V. B. Mišić, "Characterization of idle periods in IEEE 802.11e networks," in 2011 IEEE Wireless Communications and Networking Conference, 2011.

[19] X. Fafoutis, A. D. Mauro, C. Orfanidis e N. Dragoni, "Energy-efficient medium access control for energy harvesting communications," IEEE Transactions on Consumer Electronics, vol. 61, pp. 402-410, Nov. 2015.

[20] P. Grover e A. Sahai, "Shannon meets Tesla: Wireless information and power transfer," in 2010 IEEE International Symposium on Information Theory, 2010.

[21] Y. S. Gonçalves, U. C. Resende e Í. V. Soares, "Electromagnetic Energy Harvesting Using a Glass Window," Journal of Microwaves, Optoelectronics and Electromagnetic Applications, vol. 19, p. 50-59, Mar. 2020.

[22] S. Adami, P. Proynov, G. S. Hilton, G. Yang, C. Zhang, D. Zhu, Y. Li, S. P. Beeby, I. J. Craddock e B. H. Stark, "A Flexible 2.45-GHz Power Harvesting Wristband With Net System Output From -24.3 dBm of RF Power," IEEE Transactions on Microwave Theory and Techniques, vol. 66, pp. 380-395, Jan. 2018.

[23] J. F. Ensworth, S. J. Thomas, S. Y. Shin e M. S. Reynolds, "Waveform-aware ambient RF energy harvesting," in 2014 IEEE International Conference on RFID (IEEE RFID), 2014.

[24] N. Kaneda, W. R. Deal, Y. Qian, R. Waterhouse e T. Itoh, “A broadband planar Quasi-Yagi antenna,” IEEE Transactions on Antennas and Propagation, vol. 50, pp. 1158-1160, Aug. 2002.

[25] Y.-S. Chen and C.-W. Chiu, "Theoretical limits of rectifying efficiency for low-power wireless power transfer," International Journal of RF and Microwave Computer-Aided Engineering, vol. 28, 2018.

[26] R. L. R. da Silva, S. T. M. Gonçalves, C. Vollaire, A. Bréard, G. L. Ramos e C. G. do Rego, “Analysis and Optimization of Ultra-Low-Power Rectifier with High Efficiency for Applications in Wireless Power Transmission and Energy Harvesting," Journal of Microwaves, Optoelectronics and Electromagnetic Applications, vol. 19, p. 60-85, Mar. 2020.

[27] B. R. Franciscatto, V. Freitas, J. Duchamp, C. Defay e T. P. Vuong, "High-efficiency rectifier circuit at 2.45 GHz for low-input-power RF energy harvesting," in 2013 European Microwave Conference, 2013.

[28] H. P. Paz, V. S. Silva, E. V. V. Cambero, H. X. Araújo, I. R. S. Casella e C. E. Capovilla, “A survey on low power RF rectifiers efficiency for low cost energy harvesting applications," AEU - International Journal of Electronics and Communications, vol. 112, p. 152963, Dec. 2019.

[29] X. Gu, S. Hemour, L. Guo e K. Wu, "Integrated Cooperative Ambient Power Harvester Collecting Ubiquitous Radio Frequency and Kinetic Energy," IEEE Transactions on Microwave Theory and Techniques, vol. 66, pp. 4178-4190, Sep. 2018.

[30] S. Shieh e M. Kamarei, "Transient Input Impedance Modeling of Rectifiers for RF Energy Harvesting Applications," IEEE Transactions on Circuits and Systems II: Express Briefs, vol. 65, pp. 311-315, Mar. 2018.

[31] P. Salonen, L. Sydanheimo, M. Keskilammi e M. Kivikoski, “A small planar inverted-F antenna for wearable applications," IEEE - Third International Symposium on Wearable Computers, pp. 95-100, 1999.

[32] Y. Qian, W. R. Deal, N. Kaneda e T. Itoh, "Microstrip-fed Quasi-Yagi antenna with broadband characteristics," Electronics Letters, vol. 34, pp. 2194-2196, Nov. 1998.

[33] F. F. Dubrovka, O. E. Vydalko, V. I. Gouz, V. P. Lipatov e A. V. Butyrin, "Radiation and matching characteristics of phase array antennas built of printed Quasi-Yagi radiating elements," in 2013 IX Internatioal Conference on Antenna Theory and Techniques, 2013.

[34] T. Yang, D. Yang e D. Geng, "Compact planar Quasi-Yagi antenna with band-notched characteristic for WLAN and DSRC for ultra-wideband applications," IET Microwaves, Antennas Propagation, vol. 12, pp. 1239-1245, 2018.

[35] S. Zhang, Z. Tang e Y. Yin, "Wideband Planar and Printed Quasi-Yagi and Antenna and with Band-Notched and Characteristic," in Progress In Electromagnetics Research Letters, 2014.

[36] C. E. Capovilla, H. X. Araujo, A. J. S. Filho e L. C. Kretly, "Experimental Analysis of Quasi-Yagi Antenna Shapes," Przeglad Elektrotrchniczny, 2013.

[37] V. S. Silva, H. P. Paz, E. V. V. Cambero, E. T. Pereira, I. R. S. Casella e C. E. Capovilla, "Double Patch Antenna Array for Communication and Out-of-band RF Energy Harvesting," Journal of Microwaves, Optoelectronics and Electromagnetic Applications (JMOe), vol. 19, pp. AoP 356-365, Sep. 2020.

[38] A. Luzzatto e G. Shirazi, Wireless transceiver design : mastering the design of modern wireless equipment and system, 2007.

[39] X.-B. Huang, J.-J. Wang, X.-Y. Wu e M.-X. Liu, “A dual-band rectifier for low-power Wireless Power Transmission system,” 2015 Asia-Pacific Microwave Conference (APMC), vol. 2, pp. 1-3, 2015. 